\title{
Health effects of hyperbaric exposure on chamber attendants: a literature review
}

\author{
Richard Pougnet ${ }^{1,2}$, Laurence Pougnet ${ }^{1,3}$, David Lucas ${ }^{1,4}$, Anne Henckes ${ }^{1,5}$, \\ Brice Loddé $^{1,2}$, Jean-Dominique Dewitte ${ }^{1,2}$ \\ ${ }^{1}$ French Society of Medical Medicine, Brest, France \\ ${ }^{2}$ Department of Philosophy, European University of Brittany, France \\ ${ }^{3}$ Military Hospital, Clermont-Tonnerre, Brest, France \\ ${ }^{4}$ Occupational Medicine Centre of Brest (STI), France \\ ${ }^{5}$ Unit of Hyperbaric Medicine, University Hospital, Brest, France
}

\begin{abstract}
Background: Inside attendants working in hyperbaric chambers are exposed to risks related to the hyperbaric environment, handling and care. The aim of this study is to review the literature focusing on the impact of this activity on health.

Materials and methods: This is a literature review using the Medline database.

Results: Eight articles studied decompression illness (DCl). The incidence of $\mathrm{DCl}$ ranged from 0 to 37 per 100,000 sessions in hyperbaric chambers (SHC). The incidence of injuries ranged from 0 to 412 per 100,000 SHC. The most prevalent cause of accidental death was fire: 77 deaths (patients and attendants) between 1923 and 1996. Dysbaric osteonecrosis has been reported in one study only.

Conclusions: Inside attendants face risks in the chamber, even if serious health effects seems rare compared to the total number of SHC.
\end{abstract}

(Int Marit Health 2018; 69, 1: 58-62)

Key words: hyperbaric chamber, inside attendant, occupational accidents [Mesh], occupational diseases [Mesh]

\section{INTRODUCTION}

Hyperbaric oxygen therapy is a therapeutic means of administering oxygen via the lungs at a higher pressure than standard atmospheric pressure [1]. This treatment can be administered in one-place chambers or multiplace chambers and in the latter case, attendants accompany patients during recompression. The theory behind this therapy is based on work done by Haldane et al. [2] on recompression after desaturation accidents. The treatment is based on the reduction of bubble size by the oxygen pressure, in order to speed up tissue desaturation. There are many different recompression protocols depending on the type of accident, response time and how advanced the patient condition is; secondary recompression may indeed be necessary [3]. Hyperbaric oxygen therapy can be done in pressure chambers with or without the presence of an attendant. This attendant may provide technical support during hyperbaric chamber sessions, such as mechanical ventilation, blood gas measurement etc. [4]. Hyperbaric chamber attendants accompanying patients are exposed to numerous health risks.

They are mainly exposed to repeated hyperbaric chamber sessions, that is to say exposed to hyperbaric pressure. As a result, they may be exposed to the same risks as divers: decompression illness (DCl) and barotraumas [5]. DCl are mainly due to the formation of intra- or extravascular bubbles, due to the decrease in pressure [5]. DCl covers both alveolar gas emboli and venous gas emboli. Emboli are introduced into the arterial circulation. The decompression sickness is caused by in situ bubble formation from dissolved inert gas. DCl can lead to different organ damage. The most severe damages occur with the cerebral and medullary DCl. They can cause epileptic seizures or paralysis. Cochlear-vestibular DCI may cause vertigo. There 


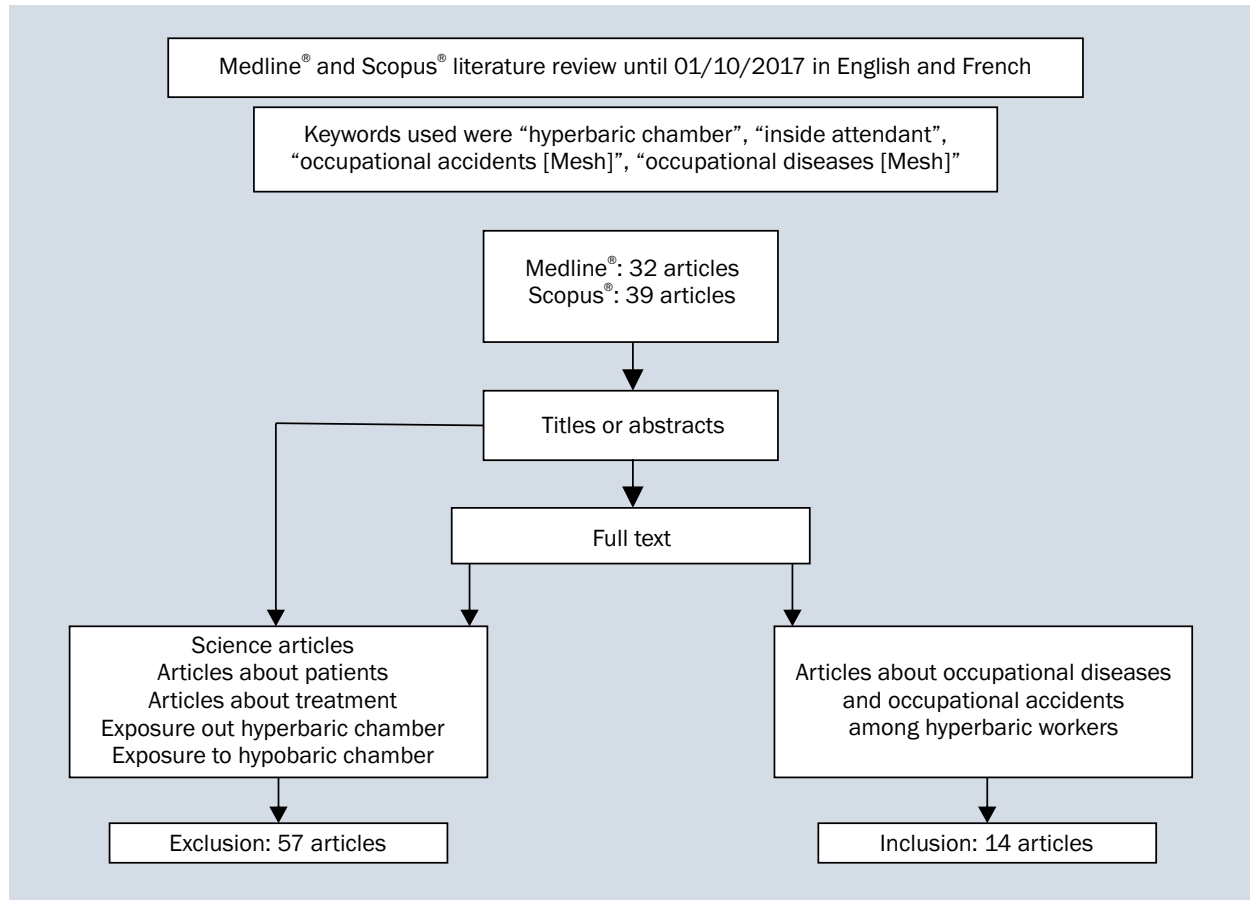

Figure 1. Flow chart

are also osteo-articular lesions such as bends and dysbaric osteonecrosis [6]. Barotrauma results from gas expansion because of the Boyle-Mariotte Law: when pressure decreases, volume increases [7]. Barotrauma are known among recreational divers [8]. The most common barotrauma are located in the thorax, but other locations are possible, especially on the eardrums and sinus $[9,10]$.

What are the risks for hyperbaric chamber workers? In the 1960s, Ledingham and Davidson [11] showed the absence of dysbaric osteonecrosis amongst attendants; they also showed that attendants only presented occasional feelings of discomfort, or passing episodes of dizziness. However, this study did not benefit from much hindsight: only 3 years.

Workers may be exposed to other health risks due to specific activities in the hyperbaric chamber. For example, some therapeutic procedures are done in the chamber. In consequence, such as other health care workers, attendants are also exposed to infection risks and risks related to handling. There is little documented information about this in literature [12]. Therefore, it would seem logical to raise questions about the impact on the health of chamber attendants. The aim of our study is, therefore, to review the information given in literature about health effects of hyperbaric exposure on chamber attendants.

\section{MATERIALS AND METHODS}

This is a Medline ${ }^{\circledR}$ and Scopus ${ }^{\circledR}$ literature review covering publications until 01/10/2017. Keywords used were "hyperbaric chamber", "inside attendant", "occupational accidents [Mesh]", "occupational diseases [Mesh]".

Criteria for inclusion were the following: English, French or Italian articles were selected. The pertinence of results was analysed according to titles and abstracts available on Medline ${ }^{\circledR}$. Studies talking about health effect on chamber attendant were retained. Manuscripts detailing effects of hyperbaric exposure on professional or recreational divers and on patients who were not caregivers were excluded. Basic science articles have been excluded, such as, studies on bubble formation after exposure, or study about leisure dive, or about hypobaric exposure (Fig. 1).

\section{RESULTS}

\section{DECOMPRESSION ILLNESS}

Decompression illness (decompression sickness and arterial gas embolism) is very rare amongst chamber attendants. A case report was published in 2012. It described a 50-year-old nurse with type II medullary $\mathrm{DCl}$, appearing $1 \mathrm{~h}$ after treatment [13]. Investigations carried out during the following months revealed the presence of a patent foramen ovale. Several studies have assessed the occurrence of $\mathrm{DCl}$ in hyperbaric chambers [12, 14-19].

Uzun et al. [17] reported a retrospective study over a 10 -year period. There was no DCl in 4532 hyperbaric sessions. As for Cooper et al. [20], they carried out a retrospective study over a 14-year period in a centre for hyperbaric medi- 
Table 1. Studies and number of health event in hyperbaric chamber attendants

\begin{tabular}{|c|c|c|c|c|}
\hline & Study & & SHC & Health effect issues \\
\hline Pougnet et al. [12] & $\begin{array}{l}\text { Retrospective study: } \\
12 \text { years }\end{array}$ & Every health effect & 8072 & $\begin{array}{l}2 \text { DCS (bends) } \\
3 \text { AGE } \\
\text { O CNOT } \\
14 \text { ENT barotrauma } \\
3 \text { exposure to blood and body fluids } \\
4 \text { handling injuries }\end{array}$ \\
\hline Matos et al. [14] & Retrospective study: 4 years & Every health effect & 5013 & 0 event \\
\hline Doolette et al. [15] & Retrospective study: 3 years & $\mathrm{DCl}$ & 1527 & 0 event \\
\hline Cooper et al. [16)] & $\begin{array}{l}\text { Retrospective study: } \\
14 \text { years }\end{array}$ & $\mathrm{DCl}$ injuries & 6062 & $\begin{array}{l}0 \mathrm{DCl} \\
25 \text { injuries }\end{array}$ \\
\hline Uzun et al. [17] & $\begin{array}{l}\text { Retrospective study: } \\
10 \text { years }\end{array}$ & $\mathrm{DCl}$ & 4532 & $\mathrm{O} \mathrm{DCl}$ \\
\hline Hansen et al. [18] & Retrospective study: 1 year & $\mathrm{DCl}$ & 1207 & $\mathrm{O} \mathrm{DCl}$ \\
\hline Witucki et al. [18] & $\begin{array}{l}\text { Retrospective study: } \\
28 \text { years }\end{array}$ & $\begin{array}{l}\mathrm{DCl} \\
\text { CNOT }\end{array}$ & 24,616 & 0 event \\
\hline Bell et al. [21] & $\begin{array}{l}\text { Retrospective study: } \\
23 \text { years }\end{array}$ & $\begin{array}{l}\mathrm{DCl} \\
\text { Chamber attendants } \\
\text { working in altitude }\end{array}$ & 28,747 & 4 DCS \\
\hline
\end{tabular}

AGE - arterial gas embolism; CNOT - central nervous oxygen toxicity; ear, nose and throat; DCl - decompression illness; DCS - decompression sickness; ENT - ear, nose and throat; $\mathrm{SHC}$ - sessions in hyperbaric chamber

cine. Out of the 6062 sessions, there was no DCl (Table 1). The incidence of DCS was therefore 0\%; 95\% confidence interval 0-0.06\%.

Witucki et al. [19] did a retrospective study over a 28-year period with the use of three recompression protocols. They reported no cases of $\mathrm{DCl}$, and no oxygen toxicity. However, their results showed that certain decompression tables were rarely used, such as the Navy Table for sessions of less than $80 \mathrm{~min}$ and their protocol for sessions of over 120 min. No events were described during this period (Table 1).

Pougnet et al. [12] reported the incidence of accidents and illnesses in chamber attendants working in 12 centres from 2005 to 2011 . The study focused on all types of accidents occurring in hyperbaric chambers. Occurrence of Arterial Gas Embolism was 37 per 100,000 exposures.

Bell et al. [21] reported the incidence of $\mathrm{DCl}$ in inside chamber attendants working in chambers which were located in cities at high altitude. This study was conducted in two centres. Decompression obligation were managed with United States Navy Standard Air Tables corrected for altitude, Bühlmann Tables, and the Nobendem ${ }^{\odot}$ calculator. In one centre, attendants were exposed to 26,900 hyperbaric sessions and $4 \mathrm{DCl}$ occurred between 1990 and 2013. In the second centre, there were 1847 hyperbaric sessions and $1 \mathrm{DCl}$ between 2008 and 2013.

\section{BAROTRAUMA}

Concerning barotrauma, Ledingham et al. [11], in the 1960 s, reported no barometric otitis in contrast with the
Pougnet et al. [12] study which showed that the majority of accidents in hyperbaric chambers were cases of barometric otitis. The incidence was 173 per 100,000 sessions.

\section{OCCURRENCE AND INCIDENCES OF OTHER HEALTH ISSUES LINKED WITH WORKING IN HYPERBARIC CHAMBERS}

Witucki et al. [19] reported 25 cases of injuries during chamber sessions per 6062 sessions; in other words the incidence was 412 per 100,000 sessions. The Pougnet et al. [12] study focused on all types of accidents. The incidence of all types of accidents was 372 per 100,000 hyperbaric sessions, which includes the incidence of accidents due to carrying/handling patients: 50 per 100,000 sessions, and the incidence of accidental blood exposure: 37 per 100,000 sessions.

A study using cerebral magnetic resonance imaging (MRI), comparing 10 chamber attendants and a control group of 10, showed that the former had more hypersignal abnormalities than the control group [23]. However, the differences were not significant $(p=0.147)$. Moreover, the groups differed with respect to tobacco consumption which could influence the results.

Osteonecrosis was studied by Ozkan et al. [23]. They performed MRI on the shoulders, hips and knees of 12 hyperbaric chamber attendants. No cases of osteonecrosis were detected. However, seniority in their work positions in the hyperbaric chamber was 3.8 years on average (extremes: 1-9). 


\section{DEATHS IN HYPERBARIC CHAMBERS}

One death from DCl was described [24]. Moreover, Sheffield and Desautels [25] submitted a literature review on fires in hyperbaric chambers. Seventy seven persons (chamber attendants and patients) died from fire in chambers between 1923 and 1996. The main supposed causes of fires were: smoking, electrical short in air conditioner, and static electricity.

\section{DISCUSSION}

Our literature review showed that occupational accidents amongst hyperbaric chamber attendants are rare. They can, however, be very serious. Therefore, the risks are far from negligible. Accidents are either associated with working in a hyperbaric environment, such as decompression accidents, or associated with caring such as accidents of blood exposure.

The methodology of our review was, however, limited. For example, certain articles could not be found on Medline. It is possible that other accidents have been reported in literature. However, on the whole, our literature review probably does not underestimate the risk of accidents in hyperbaric chambers and the occurrence of illness due to hyperbarism. Indeed, there has to be a publication angle for these occurrences [26]. Only a prospective multicentric study over several years would make it possible to accurately determine the incidence and prevalence of these health issues.

We have observed several shortcomings in studies carried out to date. Most importantly, the majority of articles have only studied DCl. However, hyperbaric chamber attendants are exposed to many other professional risks, such as caring and handling. The cramped conditions in some chambers could increase these risks compared with other medical care structures. Likewise, few studies concentrate on the long term health effect of hyperbaric exposure, such as osteonecrosis. Regarding the single study reporting on osteonecrosis, the group was small with only 12 subjects. Indeed, the prevalence of osteonecrosis amongst professional divers has been reported to vary between $0 \%$ and $70 \%$ [6]. Amongst divers respecting European and North American decompression tables, this prevalence was low and the illness only appeared after several years of exposure. A carefully designed and detailed study of injuries and illnesses in chamber attendants would, therefore, be of interest.

Certain hyperbaric protocols have not been studied yet in sufficient detail to disclose their potential risk for hyperbaric chamber attendants [19]. In the Witucki et al. [19] study, only the number of dives with an adapted protocol for short hyperbaric exposure was low: 229 over 28 years. Their overall results showed a low probability of $\mathrm{DCl}$ and oxygen toxicity accidents.
No matter how low the probability might be, the risk remains significant when the potential seriousness of these accidents is taken into account: for example, the case of the reported death of a nurse [24]. This is the background for the study by Cooper et al. [20] reporting the incidence of venous gas embolism in chamber attendants under real-life conditions using Doppler monitoring. They were able to test their tables and carry out a risk assessment for attendants. This method was used by other teams and has led to the elimination of certain tables deemed too risky with regards to bubble formation [27]. Moreover, the use of transcranial Doppler could also be used as primary prevention for detecting foramen ovale in chamber attendants. Indeed, the persistence of a patent foramen ovale represents a risk to develop DCI [28, 29]. However, there is no consensus on this subject.

As far as secondary prevention is concerned, hyperbaric chamber attendants should be aware of the incurred risks. They should also receive training on early detection of $\mathrm{DCl}$ symptoms and, while working, be suspicious of $\mathrm{DCl}$ occurring [26].

Other teams specify protocols for emergency measures in the case of accidents in hyperbaric chambers [19]: such as the availability of oxygen masks. These emergency measures should also take into consideration all types of accident. For example, one of the main risks is fire; one literature review showed that fire was the cause of 77 deaths (patients and chamber attendants) during the $20^{\text {th }}$ century in hyperbaric chambers [30].

It is difficult to compare protocols from one article to another: some of them have extrapolated information regarding protocols adapted to diving in water. They transposed this information to chamber sessions. This, in particular, was the case for the Witucki et al. team [19]. Other teams have developed other protocols. For example, Larsson et al. [31] suggest that the chamber attendants should breathe hyperoxic nitrogen-oxygen gas mixtures (Nitrox), thereby making sessions of over 200 min possible. The safety of chamber attendants breathing Nitrox remains to be verified. A prospective study would be necessary to do these types of comparisons.

\section{CONCLUSIONS}

Work in hyperbaric chambers exposes people to numerous risks. During the $20^{\text {th }}$ century, several people have died, in particular in fires, and only one of them died following decompression sickness. As for chamber attendants, $\mathrm{DCl}$ is the main complication studied and reported, although other types of accidents are more common such as injuries and illnesses directly related to the care of patients. 


\section{REFERENCES}

1. Haute Autorité de Santé. Oxygénothérapie hyperbare (French National Authority for Health. Hyperbaric Oxygen Therapy).http://www.hassante.fr/portail/jcms/r_1498758/fr/oxygenotherapie-hyperbare.

2. Haldane JS, Boycott AA, Damant GC. The Prevention of Compressed-air Illness. J Hyg (Lond). 1908; 8(3): 342-443, indexed in Pubmed: 20474365.

3. Bergmann E, Barthélémy A, Grandjean B. Thérapeutique hyperbare des accidents de désaturation (Hyperbaric therapy for desaturation accidents). In: Broussolle B, Méliet JL, Coulange M. ed. Physiologie et médecine de la plongée. Ellipses, Paris 2006.

4. Moon RE, Hart BB. Operational use and patient monitoring in a multiplace hyperbaric chamber. Respir Care Clin N Am. 1999; 5(1): 21-49, indexed in Pubmed: 10205812.

5. Vann RD, Butler FK, Mitchell SJ, et al. Decompression illness. Lancet. 2011; 377(9760): 153-164, doi: 10.1016/S01406736(10)61085-9, indexed in Pubmed: 21215883.

6. Uguen M, Pougnet R, Uguen A, et al. Dysbaric osteonecrosis among professional divers: a literature review. Undersea Hyperb Med. 2014; 41(6): 579-587, indexed in Pubmed: 25562949.

7. Haller C, Guenot C, Azagury D, et al. [Intestinal barotrauma after diving-mechanical ileus in incarceration of the last loop of the small intestine between a mobile cecum and sigmoid]. Swiss Surg. 2003; 9(4): 181-183, indexed in Pubmed: 12974175.

8. Jansen S, Meyer MF, Boor M, et al. Repetitive freshwater diving: risk factors and prevalence of barotrauma. Undersea Hyperb Med. 2017; 44(5): 407-414, indexed in Pubmed: 29116695.

9. Ergözen S. Preventable Diving-related Ocular Barotrauma: A Case Report. Turk J Ophthalmol. 2017; 47(5): 296-297, doi: 10.4274/ tjo.67503, indexed in Pubmed: 29109900.

10. Vaezeafshar R, Psaltis AJ, Rao VK, et al. Barosinusitis: Comprehensive review and proposed new classification system. Allergy Rhinol (Providence). 2017; 8(3): 109-117, doi: 10.2500/ar.2017.8.0221, indexed in Pubmed: 29070267.

11. Ledingham I, Davidson JK. Hazards in Hyperbaric Medicine. BMJ. 1969; 3(5666): 324-327, doi: 10.1136/bmj.3.5666.324.

12. Pougnet R, Henckes A, Pougnet L, et al. Occupational accidents among attendants inside hyperbaric chambers in France. Med Lav. 2015; 106(1): 17-22, indexed in Pubmed: 25607284.

13. Johnson-Arbor K. Type II decompression sickness in a hyperbaric inside attendant. Undersea Hyperb Med. 2012; 39(5): 915-919, indexed in Pubmed:23045920.

14. Matos LA, Lopez EA, Sanchez CA, Leon K (2002). Incidence of morbidity in a multiplace hyperbaric medicine practice. $h$ ttp://archive. rubicon-foundation.org/1217 (accessed 01 July 2014).

15. Doolette D, Goble S, Pirone C. Health outcome of hyperbaric inside attendants following compressed-air exposure and oxygen decompression. SPUMS J. 2004; 34: 63-67.

16. Cooper PD, Van den Broek C, Smart DR. Hyperbaric chamber attendant safety II: 14-year health review of multiplace chamber attendants. Diving Hyperb Med. 2009; 39(2): 71-76, indexed in Pubmed: 22753199.
17. Uzun G, Mutluoğlu M, Ay H, et al. Decompression sickness in hyperbaric nurses: retrospective analysis of 4500 treatments. J Clin Nurs. 2011; 20(11-12): 1784-1787, doi: 10.1111/j. 1365-2702.2010.03600.x, indexed in Pubmed: 21554460.

18. Hansen MB, Jansen T, Sifakis MB, et al. Chamber personnel's use of Nitrox 50 during hyperbaric oxygen treatment: a quality study-research report. Undersea Hyperb Med. 2013; 40(5): 395-402, indexed in Pubmed: 24224283.

19. Witucki P, Duchnick J, Neuman T, et al. Incidence of DCS and oxygen toxicity in chamber attendants: a 28-year experience. Undersea Hyperb Med. 2013; 40(4): 345-350, indexed in Pubmed: 23957205.

20. Cooper PD, Van den Broek C, Smart DR, et al. Hyperbaric chamber attendant safety I: Doppler analysis of decompression stress in multiplace chamber attendants. Diving Hyperb Med. 2009; 39(2): 63-70, indexed in Pubmed: 22753198.

21. Bell J, Thombs PA, Davison WJ, et al. Decompression tables for inside chamber attendants working at altitude. Undersea Hyperb Med. 2014; 41(6): 505-513, indexed in Pubmed: 25562942.

22. Ors F, Sonmez G, Yildiz S, et al. Incidence of ischemic brain lesions in hyperbaric chamber inside attendants. Adv Ther. 2006; 23(6): 1009-1015, doi:10.1007/bf02850221, indexed in Pubmed: 17276968.

23. Ozkan H, Uzun G, Yildiz S, et al. MRI screening of dysbaric osteonecrosis in hyperbaric-chamber inside attendants. J Int Med Res. 2008; 36(2): 222-226, doi: 10.1177/147323000803600202, indexed in Pubmed: 18380930.

24. Hyperbaric chamber nurse dies of decompression sickness; unit gets OK. Hosp Secur Saf Manage. 1992; 13(5): 3, indexed in Pubmed: 10122695.

25. Sheffield PJ, Desautels DA. Hyperbaric and hypobaric chamber fires: a 73-year analysis. Undersea Hyperb Med. 1997; 24(3): 153-164, indexed in Pubmed: 9308138.

26. Perdrizet GA. Type II DCS in an inside hyperbaric attendant: commentary. Undersea Hyperb Med. 2012; 39(5): 869, indexed in Pubmed: 23045913.

27. Risberg J, Englund M, Aanderud L, et al. Venous gas embolism in chamber attendants after hyperbaric exposure. Undersea Hyperb Med. 2004; 31(4): 417-429, indexed in Pubmed: 15686273.

28. Lier H, Schroeder S, Hering R. [Patent foramen ovale: an underrated risk for divers?]. Dtsch Med Wochenschr. 2004; 129(1-2): 27-30, doi: 10.1055/s-2004-812652, indexed in Pubmed: 14703578.

29. Germonpré P. Patent foramen ovale and diving. Cardiol Clin. 2005; 23(1): 97-104, doi: 10.1016/j.ccl.2004.10.005, indexed in Pubmed: 15676273.

30. Sheffield PJ, Pirone CJ. Decompression sickness in inside attendants. In: Workmann WT. ed. Hyperbaric facility safety: a practical guide. Best Publishing Company, Flagstaff 1999: 643-663.

31. Larsson AC, Uusijärvi J, Frånberg 0 , et al. Nitrox permits direct exit for attendants during extended hyperbaric oxygen treatment. Undersea Hyperb Med. 2012; 39(1): 605-612, indexed in Pubmed: 22400451. 